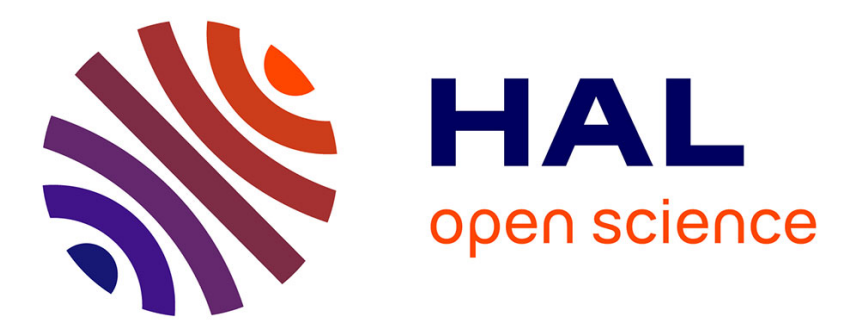

\title{
Spectroscopy and optical characterization of thulium doped TZN glasses
}

H Gebavi, D Milanese, R Balda, S Chaussedent, M Ferrari, J Fernandez, M

Ferraris

\section{- To cite this version:}

H Gebavi, D Milanese, R Balda, S Chaussedent, M Ferrari, et al.. Spectroscopy and optical characterization of thulium doped TZN glasses. Journal of Physics D: Applied Physics, 2010, 43 (13), pp.135104. 10.1088/0022-3727/43/13/135104 . hal-00569566

\section{HAL Id: hal-00569566 https://hal.science/hal-00569566}

Submitted on 25 Feb 2011

HAL is a multi-disciplinary open access archive for the deposit and dissemination of scientific research documents, whether they are published or not. The documents may come from teaching and research institutions in France or abroad, or from public or private research centers.
L'archive ouverte pluridisciplinaire HAL, est destinée au dépôt et à la diffusion de documents scientifiques de niveau recherche, publiés ou non, émanant des établissements d'enseignement et de recherche français ou étrangers, des laboratoires publics ou privés. 


\title{
Spectroscopy and optical characterization of thulium doped TZN
}

\section{glasses}

H. Gebavi ${ }^{1, *}$, D. Milanese ${ }^{1}$, R. Balda ${ }^{2}$, S. Chaussedent ${ }^{3}$, M. Ferrari ${ }^{4}$, J. Fernandez $^{2}$, M. Ferraris $^{1}$

${ }^{1}$ Dipartimento di Scienza dei Materiali ed Ingegneria Chimica, Politecnico di Torino, Corso Duca degli Abruzzi 24, 10129 Torino, Italy, email: gebavi@ yahoo.com

${ }^{2}$ Departamento de Fisica Aplicada I, Escuela Superior de Ingenieros, Alda. Urquijo s/n 48013 Bilbao, Spain and Center of Materials Physics CSIC-UPV/EHU and Donostia International Physics Center, Apartado 1072, 20080 San Sebastian, Spain

${ }^{3}$ Laboratoire POMA-FRE CNRS 2988, Universite d'Angers, 2 bd. Lavoisier, 49045 Angers, France

${ }^{4}$ CNR-IFN, CSMFO Lab., via alla Cascata 56/C, 38050 Povo-Trento, Italy

\begin{abstract}
This paper reports spectroscopic properties of the ${ }^{3} \mathrm{H}_{4}$ and ${ }^{3} \mathrm{~F}_{4} \mathrm{Tm}^{3+}$ levels in TZN glass host with a concentration range from 0.82 to $2210^{20} \mathrm{~cm}^{-3}$. Precise refractive index measurements are performed on five different wavelengths by the prism coupling method. Judd - Ofelt intensity parameters have been determined in order to obtain transition rate, branching ratio, and radiative lifetime. Spectroscopy measurements showed the most promising concentration for $1.8 \mu \mathrm{m}$ short cavity laser emission at $6.8410^{20} \mathrm{~cm}^{-3} \mathrm{Tm}^{3+}$ with a $24 \%$ quantum efficiency
\end{abstract}


and upper limit concentration of $1110^{20} \mathrm{~cm}^{-3} \mathrm{Tm}^{3+}$. Energy transfer microparameters and critical ion distance are determined for both emission levels in the framework of diffusion limited regime and dipole - dipole interaction.

Keywords: tellurite glass, thulium, Judd-Ofelt, refractive index, energy transfer

PACS: 42.70.Hj; 78.40.-q; 78.55.-m; 78.55.Qr.

\section{Introduction}

Huge scientific effort was devoted in investigation materials and devices for emission in the infrared wavelength region where optical telecommunications play their main role, in the so called S-band from 1460 to $1530 \mathrm{~nm}, \mathrm{C}-$ band from 1530 to $1565 \mathrm{~nm}$ and L-band from 1565 to $1625 \mathrm{~nm}$. On the other hand, infrared (IR) domain at wavelengths around $2 \mu \mathrm{m}$ includes different properties and offers a number of applications. First of all, there is an atmospheric transparency window that allows remote sensing in free space. Detection of water vapor is also possible in such range of wavelengths, thanks to strong vibrational absorption lines [1].

Thulium $\left(\mathrm{Tm}^{3+}\right)$ is a good choice for IR domain applications because of its absorption at $790 \mathrm{~nm}$ which is available using commercial diodes, and its interesting emission at $\sim 1.8 \mu \mathrm{m}$ for a number of sensing and medical applications [2]. In addition, the phonon assisted energy

transfer process called "cross relaxation" $\left(\mathrm{CR}:{ }^{3} \mathrm{H}_{4},{ }^{3} \mathrm{H}_{6} \rightarrow{ }^{3} \mathrm{~F}_{4},{ }^{3} \mathrm{~F}_{4}\right)$ allows obtaining two ions in upper laser level for each pumping photon, which enhances the $1.8 \mu \mathrm{m}$ emission and is one of the main reasons for utilizing thulium as an active ion for IR applications. An important 
feature of $\mathrm{Tm}^{3+}$ as emitter in a host glass is the possibility of continuous tuning in the $1.8-2$ $\mu \mathrm{m}$ region depending on the host matrix, thanks to its wide emission peak. Tunability of Tm is also demonstrated in the $2.2-2.46 \mu \mathrm{m}$ region in Tm:YLF host (crystal host) for small dopant concentrations [3].

Another interesting emission in the eye-safe region and telecommunication S-band is at $1.47 \mu \mathrm{m}$ which occurs for ${ }^{3} \mathrm{H}_{4} \rightarrow{ }^{3} \mathrm{~F}_{4}$ transition. However, inverted population for such lasing transition is more difficult to obtain without depopulating the lower energy level since the lifetime of ${ }^{3} \mathrm{H}_{4}$ level is shorter than the one of ${ }^{3} \mathrm{~F}_{4}$ which creates the so called 'bottleneck' effect.

The aim of this study is a detailed glass examination in order to improve fiber lasing emission and develop short cavity fiber laser with lasing emission in the infrared region. Advantages of a short laser cavity lies in a background loss reduction which occurs due to scattering or contaminants absorption and so can yield the same gain in a shorter device [4] and narrow emission linewidth. Such objective requires highly doped active ion concentration which carries a potential risk of clustering and increasing of excited state absorption effect (ESA) or reverse cross-relaxation. Fiber lasers have potential for narrow linewidth (few kHz) applications compared with for example semiconductor lasers ( MHz). [4]. Narrow linewidth is specially related to single frequency laser which operates in a single resonator mode emitting quasi monochromatic radiation with very small linewidth and phase noise which guarantees spectral purity. The origin of the phase noise is spontaneous emission of the gain medium related with optical and technical noise influence. The short cavity should give contribution to stabile long-term, single mode operation avoiding hopping mode [5]. On the other hand, too narrow linewidth can create problems due to Brillouin scattering which can be partially reduced by resonator length decrease [5]. 
As the host matrix tellurite glass is used because of its unique properties whilst the IR emission is ensured with thulium ions. In a previous work [6], some of the authors reported a characterization of some structural and optical properties of $\mathrm{Tm}^{3+}$ ions in $75 \mathrm{TeO}_{2}-20 \mathrm{ZnO}-$ $5 \mathrm{Na}_{2} \mathrm{O}$ tellurite glass. In this work, we report together with Judd-Ofelt analysis to calculate transition rates, radiative lifetimes, and branching ratios the study of the effect of concentration on the ${ }^{3} \mathrm{H}_{4} \rightarrow{ }^{3} \mathrm{~F}_{4}$ and ${ }^{3} \mathrm{~F}_{4} \rightarrow{ }^{3} \mathrm{H}_{6}$ emissions of $\mathrm{Tm}^{3+}$. Wide concentration range strongly changes the nature of the ion-ion interaction which is characterized by quenching parameters. The analysis of the fluorescence decays from the ${ }^{3} \mathrm{H}_{4}$ level indicates the presence of a dipole-dipole quenching process assisted by energy migration. Energy transfer microparameters and critical ion distance are determined for both emission levels ${ }^{3} \mathrm{H}_{4}$ and ${ }^{3} \mathrm{~F}_{4}$, in the framework of diffusion - limited regime and dipole - dipole interaction.

\section{Experimental techniques}

\subsection{Glass fabrication}

Glasses were prepared by melt quenching from mix powder batches, inside a glove box in a dry atmosphere with water content of about $7 \mathrm{ppm}$. The chemicals employed (together with their purity) were the following: $\mathrm{TeO}_{2}(99+\%), \mathrm{ZnO}(99.99 \%), \mathrm{Na}_{2} \mathrm{CO}_{3}$ (99.995\%), $\mathrm{Tm}_{2} \mathrm{O}_{3}(99.99 \%)$. Relative molar ratio of the host glass constituent oxides was kept the same for all samples, regardless of Tm doping. The fabricated samples were based on the host glass composition $75 \mathrm{TeO}_{2}: 20 \mathrm{ZnO}: 5 \mathrm{Na}_{2} \mathrm{O}$ and doped with increasing amounts of $\mathrm{Tm}^{3+}$. Nine different samples were prepared with the following $\mathrm{Tm}^{3+}$ mol\% content with respect to the glass constituent oxides: $0.36,1,2.1,3,4,5,6,7$ and 10 . Glass melting was carried out in Pt crucibles at around $900{ }^{\circ} \mathrm{C}$ for $2-3 \mathrm{~h}$, followed by pouring on a preheated 
brass plate at $300{ }^{\circ} \mathrm{C}$ and annealing followed. The whole process required around $20 \mathrm{~h}$ of operation.

\subsection{Glass characterization: optical properties}

Glasses were cut into 1-2 mm thick slices and polished to an optical quality. UV-VIS spectroscopy in transmission was carried out with a Varian Cary 500 spectrometer in order to assess the absorption spectra of the rare earth doped glasses.

Refractive index was measured for all samples at five different wavelengths $(533,825$, 1061, 1312 and $1533 \mathrm{~nm}$ ) by the prism coupling technique (Metricon, model 2010). The resolution of the instrument was of \pm 0.0001 . Five scans were used for each measurement. Standard deviation in refractive index at different points of the same sample was around \pm 0.0003 .

The steady-state emission measurements were made with a Ti-sapphire ring laser $(0.4$ $\mathrm{cm}^{-1}$ linewidth) at $793 \mathrm{~nm}$ of excitation wavelength. The fluorescence was analyzed with a 0.25 monochromator, and the signal was detected by a $\mathrm{PbS}$ detector and finally amplified by a standard lock-in technique. Lifetime measurements were obtained by exciting the samples with a Ti-sapphire laser pumped by a pulsed frequency doubled Nd:YAG laser $(9 \mathrm{~ns}$ pulse width), and detecting the emission with a Hamamatsu R5509-72 photomultiplier. Since the R5509-72 PMT showed weak response at $\sim 1800 \mathrm{~nm}$, the decay curves from ${ }^{3} \mathrm{~F}_{4}$ level $\left(\mathrm{Tm}^{3+}\right)$ were performed by collecting the luminescence at the emission wavelength of $1680 \mathrm{~nm}$. Data were processed by a Tektronix oscilloscope. All measurements were performed at room temperature. 


\section{Experimental results}

\subsection{Glass table and refractive index measurements}

Table 1 shows the samples examined in this study together with their dopant concentration and refractive index values at 633, 825, 1061, 1312 and $1533 \mathrm{~nm}$ respectively.

\section{Table 1}

The refractive index decreases with increasing $\mathrm{Tm}^{3+}$ concentration and increasing wavelength [6]. Values of the refractive index of the sample T5 are used for obtaining Cauchy fitting parameters to be used in the Judd - Ofelt theory (3.2).

\subsection{Judd-Ofelt theory results}

The VIS-NIR absorption measurement was obtained in the $300-2100 \mathrm{~nm}$ range on the sample doped with $11.310^{20} \mathrm{~cm}^{-3} \mathrm{Tm}^{3+}$, T5 (58151 ppm of $\mathrm{Tm}^{3+}$ ). Absorption transitions originating in the ground state are assigned as ${ }^{1} \mathrm{G}_{4},{ }^{3} \mathrm{~F}_{2,3},{ }^{3} \mathrm{H}_{4},{ }^{3} \mathrm{H}_{5}$ and ${ }^{3} \mathrm{~F}_{4}$ (Fig.1.).

Fig. 1

Judd-Ofelt (J-O) theory is used to calculate transition probabilities between different manifolds, radiative lifetimes and emission branching ratios as found in the literature $[7,8]$. 
Obtained values of $\mathrm{J}-\mathrm{O}$ parameters by using five main absorption bands are summarized in Table 2 together with the literature overview.

Table 2.

The absorption bands of $\mathrm{Tm}^{3+}$ are all dominated by electric dipole transitions except the transition ${ }^{3} \mathrm{H}_{6} \rightarrow{ }^{3} \mathrm{H}_{5}$, which contains electric-dipole and magnetic-dipole contributions which can be calculated as shown in the literature [8]. The largest error in a J-O calculation is the assumption that all Stark levels of a given multiplet are equally populated. An overview of radiative rate, lifetime, and branching ratio of the main transitions is given in Table 3 .

\section{Table 3}

In section 3.4 is introduced the experimental value obtained on a low doped sample and considered as radiative lifetime. Comparison of lifetime results given by the $\mathrm{J}-\mathrm{O}$ theory with experimental values and the results from other authors is presented in Table 4.

Table 4

All reported data indicate the radiative value of ${ }^{3} \mathrm{H}_{4}$ level as $\sim 0.35 \mathrm{~ms}$ whilst a significant discrepancy for ${ }^{3} \mathrm{~F}_{4}$ level between $\mathrm{J}-\mathrm{O}$ theory and the experimental values is observed. 


\subsection{Emission spectra}

Emission spectra of ${ }^{3} \mathrm{H}_{4} \rightarrow{ }^{3} \mathrm{~F}_{4}$ and ${ }^{3} \mathrm{~F}_{4} \rightarrow{ }^{3} \mathrm{H}_{6}$ transitions correspond to 1475 and 1847 $\mathrm{nm}$ emissions, respectively. Fig 2 shows the spectra of all prepared samples: they are normalized on the area under the ${ }^{3} \mathrm{H}_{4}$ level emission band. Some of the emissions (sample T7 and T4) from ${ }^{3} \mathrm{~F}_{4}$ level are shifted towards longer wavelengths which is due to measurements on thicker samples and therefore affected by reabsorption effects.

Fig. 2

Fig. 3 a presents the ratio between the areas under ${ }^{3} \mathrm{H}_{4}$ and ${ }^{3} \mathrm{~F}_{4}$ emission bands. Increase of ${ }^{3} \mathrm{~F}_{4}$ emission with dopant increase is likely due to CR between ${ }^{3} \mathrm{H}_{4} \rightarrow{ }^{3} \mathrm{~F}_{4}$ and ${ }^{3} \mathrm{~F}_{4} \rightarrow{ }^{3} \mathrm{H}_{6}$ transitions. Saturation occurs for $\mathrm{Tm}^{3+}$ concentrations higher than $6 \mathrm{~mol} \%$ of $\mathrm{Tm}^{3+}$. In that case ${ }^{3} \mathrm{H}_{4}$ level is totally depleted by $\mathrm{CR}$ to ${ }^{3} \mathrm{~F}_{4}$ level and no further increase in the $1847 \mathrm{~nm}$ emission is possible.

Fig. $3 \mathrm{~b}$ presents the ratio between the same two emission peaks normalized to the number of ions. This ratio could give an insight about the concentration dependence of the efficiency of the cross-relaxation process. Two regions can be observed: the first one, when the emission at $1847 \mathrm{~nm}$ increases, up to $3 \mathrm{~mol} \%$, and the second one for higher concentrations when it decreases. The peak value is for the sample doped with $3 \mathrm{~mol} \%$ of $\mathrm{Tm}^{3+}$. CR process is beneficial up to $3 \mathrm{~mol} \%$ of $\mathrm{Tm}^{3+}$ considering the amount of dopant $\mathrm{Tm}^{3+}$ ions. Above this concentration, quenching of ${ }^{3} \mathrm{~F}_{4}$ level begins.

Fig. 3 
Emission cross section can be calculated by using the expression [9]: $\sigma_{e m .}=\frac{\lambda_{p}^{4} \beta}{8 \pi n^{2} c \tau_{0} \Delta \lambda_{\text {eff }}}$, where $\lambda_{\mathrm{p}}$ is the peak fluorescence wavelength, $\beta$ is branching ratio, $\mathrm{n}$ is refractive index, $\mathrm{c}$ is light velocity, $\tau_{0}$ is radiative lifetime and $\Delta \lambda_{\text {eff. }}$ is the effective linewidth.

The effective linewidth of the transition has been calculated by using the relation $\Delta \lambda_{\text {eff }}=\int \frac{\mathrm{I}(\lambda)}{\mathrm{I}_{\max }} \mathrm{d} \lambda$. The emission cross section obtained values for level ${ }^{3} \mathrm{H}_{4}$ are in the range 2.6$2.810^{-25} \mathrm{~m}^{2}$ whilst for level ${ }^{3} \mathrm{~F}_{4}$ emission values of the T0.36 sample is $5.410^{-25} \mathrm{~m}^{2}$. This value is in agreement with those reported in the literature for tellurite glasses $[8,9]$ and higher than those reported in fluoride and oxyfluoride glasses [10].

Fluorescence waveforms were measured at $1475 \mathrm{~nm}\left({ }^{3} \mathrm{H}_{4}\right.$ level $)$ and $1680 \mathrm{~nm}\left({ }^{3} \mathrm{~F}_{4}\right.$ level) by pumping with $793 \mathrm{~nm}$ excitation wavelength at room temperature. Further experimental results and discussion will be separately presented for both emissions.

\subsection{Concentration quenching of the ${ }^{3} \mathrm{H}_{4}$ emission}

The decay curves for the ${ }^{3} \mathrm{H}_{4}$ level at $1475 \mathrm{~nm}$ were found to be non-exponential for all dopant concentrations except for the $0.36 \mathrm{~mol} \% \mathrm{Tm}^{3+}$ doped sample (T0.36) which shows an exponential decay i.e. linear curve in semilogarithmic scale, as reported in Fig. 4.

Fig. 4 
Average lifetime values for the non-exponential decays are calculated by utilizing the expression [13]: $\langle\tau\rangle=\frac{1}{I(t=0)} \cdot \int I(t) d t$. Calculated lifetime values from this expression are given in Table 5. The lifetime value of the lowest doped sample T0.36 is taken as the radiative lifetime in further assumptions.

\section{Table 5}

Photoluminescence quantum efficiency $(\eta)$ is expressed as a ratio between number of emitted and incident excitation photons. By the formula, $\eta$ can be described either as a ratio between radiative and total decay or as the ratio between measured and radiative lifetime $\eta=$ $\tau_{\mathrm{m}} / \tau_{0}[14]$. Quantum efficiencies of all glass samples are reported in Table 5.

The reduction of the lifetime and quantum efficiency of the $1475 \mathrm{~nm}$ emission as concentration increases, together with the change from exponential to nonexponential decays have been previously observed in Tm-doped glasses and attributed to cross-relaxation processes such as ${ }^{3} \mathrm{H}_{4},{ }^{3} \mathrm{H}_{6} \rightarrow{ }^{3} \mathrm{~F}_{4},{ }^{3} \mathrm{~F}_{4}$. In this process part of the energy of an ion in level ${ }^{3} \mathrm{H}_{4}$ is transferred to another ion in the ground state with both ions ending up in level ${ }^{3} \mathrm{~F}_{4}$.

Energy transfer (ET) occurs when more than one optically active center are present inside the critical domain. Its value depends on sensitizer emission and activator absorption spectra overlapping, mutual ion distance, quantum transition efficiency, relative orientation of sensitizer and acceptor transition dipoles [15]. ET processes can be considered as radiative or non-radiative. In the case of radiative processes characterized by photon transfer, there is no coupling between active ions, and their emission probability will remain the same. However, 
non-radiative energy migration can be described by Coulomb interaction via electromagnetic field or by quantum mechanic and virtual photon exchange. The latter can be transferred to a classical mechanic frame by a dipole oscillator interaction assumption. Dipole - dipole (dd) and multipole interaction theory is described in the work by Dexter and Förster [16].

Non-radiative energy transfer processes such as cross-relaxation are generally described in terms of three limiting cases: a) one step process involving direct energy transfer, b) diffusion - limited relaxation, and c) fast diffusion [17]. In the case of very fast diffusion, the decay of the donor fluorescence is purely exponential.

Decay curve of sample T0.36 (Fig. 4) shows a clear exponential decay and can be described by direct energy transfer model. However, for the higher dopant concentration it was not the case. Difference between diffusion limited process and fast diffusion can be determined by the concentration dependence of the quenching rate $\mathrm{R}_{\mathrm{Q}}$ given by:

$$
R_{Q}=\frac{1}{\tau_{m}}-\frac{1}{\tau_{0}}
$$

- where $\tau_{\mathrm{m}}$ is the measured value and $\tau_{0}$ the radiative lifetime.

A quadratic dependence $\mathrm{R}_{\mathrm{Q}} \sim \mathrm{N}^{2}$ corresponds to diffusion - limited processes whilst the linear $\mathrm{R}_{\mathrm{Q}} \sim \mathrm{N}$ infers fast diffusion processes [18]. Hence a logarithmic plot of the quenching rate versus concentration should show a slope equal to two if the decay is diffusion -limited and equal to one in the case of fast diffusion.

Fig.5 
Figure 5 shows a logarithmic plot of the quenching rate of the ${ }^{3} \mathrm{H}_{4}$ level as a function of the $\mathrm{Tm}^{3+}$ concentration. As can be observed in this concentration range the slope is 2.2 which indicate the presence of a dipole-dipole mechanism in the framework of a diffusionlimited regime. As we have mentioned before, for $\mathrm{Tm}^{3+}$ concentrations higher than $6 \mathrm{~mol} \%$, the emission from ${ }^{3} \mathrm{H}_{4}$ level is nearly totally quenched due to $\mathrm{CR}$ to ${ }^{3} \mathrm{~F}_{4}$ level.

Non-exponential decay curves of ${ }^{3} \mathrm{H}_{4}$ emissions which are attributed to diffusion limited regime when energy transfer between sensitizers and sensitizer to activator via dipole - dipole interaction occurs can be fitted by the Yokota - Tanimoto (Y-T) equation [19]:

$$
\phi(t)=\phi(0) \cdot e^{-t / \tau_{0}} \cdot \exp \left[-\frac{4}{3} \cdot \pi^{3 / 2} \cdot N \cdot\left(C_{S A} \cdot t\right)^{1 / 2} \cdot\left(\frac{1+10.87 x+15.5 x^{2}}{1+8.743 x}\right)^{3 / 4}\right]
$$

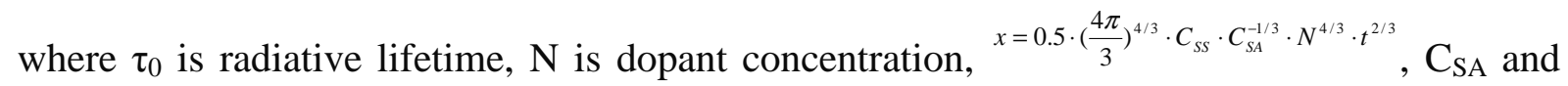
$\mathrm{C}_{\mathrm{SS}}$ are ET microparameters for SA and SS interaction respectively. The following parameterization can be used: ${ }^{A=\frac{4}{3} \pi^{3 / 2} \cdot N \cdot C_{S 1}^{1 / 2}}, \quad B=0.5 \cdot\left(\frac{4 \pi}{3}\right)^{4 / 3} \cdot C_{S S} \cdot C_{S A}^{-1 / 3} \cdot N^{4 / 3}$. Value of parameter B can be expressed also as $\mathrm{B}=\mathrm{DC}_{\mathrm{SA}^{-1 / 3}}$ with $\mathrm{D}$ as a diffusion coefficient [20]. Example of the fit curve for the sample $\mathrm{T} 1$ in a semilogarithmic plot is shown in fig. 6 . For $\mathrm{Tm}^{3+}$ doping levels higher than $6.8410^{20} \mathrm{~cm}^{-3}$, the emission from ${ }^{3} \mathrm{H}_{4}$ level is practically quenched.

Fig. 6

Obtained values of Y-T parameters are shown in Table 6. 
This table also shows the values for the critical radius $\mathrm{R}_{0}$. The critical distance $\mathrm{R}_{0}$ taken as $R_{0}^{6}=\tau_{0} \mathrm{C}_{\mathrm{SA}}$ indicates that the energy transfer can occur among ions which are located within a given domain. A longer critical distance value means faster energy transfer.

Parameters A and B can be extended for the various concentration values by plotting them versus dopant concentration (Fig 7a, b).

\section{Fig 7}

From the slope of the parameter $\mathrm{A}, \mathrm{C}_{\mathrm{SA}}=2.1510^{-50} \mathrm{~m}^{6} / \mathrm{s}$ can be obtained which in turn is used together with the slope of the parameter $\mathrm{B}$ to give $\mathrm{C}_{\mathrm{SS}}=1.1610^{-50} \mathrm{~m}^{6} / \mathrm{s}$. These values are of the same order as those obtained from fits of the experimental decays from level ${ }^{3} \mathrm{H}_{4}$ to the Yokota - Tanimoto model. In this case $\mathrm{C}_{\mathrm{SS}}<\mathrm{C}_{\mathrm{SA}}$ so the probability of energy transfer to acceptor is higher than to sensitizer.

Another possibility to evaluate the effect of the energy transfer on the lifetimes of the ${ }^{3} \mathrm{H}_{4}$ level is to use rate equation formalism. By using this formalism and considering a low excitation density, Camargo et al. [21] obtained the following expression for the lifetimes of the ${ }^{3} \mathrm{H}_{4}$ level as a function of concentration:

$$
\tau_{\text {calc. }}=\frac{\tau_{0}}{1+W_{E T} \cdot N \cdot \tau_{0}}
$$

where $\tau_{0}$ is the radiative lifetime of ${ }^{3} \mathrm{H}_{4}$ level, $\mathrm{W}_{\mathrm{ET}}$ the total energy transfer for dd interaction and $\mathrm{N}$ sensitizer ion concentration. In this study ET microparameters of dd interaction are obtained trough Yokota - Tanimoto fitting and not by Kushida model. Therefore is taken: 
$W_{E T}^{d d}=28\left(C_{S A}^{d d}\right)^{1 / 4}\left(C_{S S}^{d d}\right)^{3 / 4} N$ [22]. $\mathrm{W}_{\mathrm{ET}}$ should include contribution from dq and qq interaction which is in our case excluded. Values of calculated and measured lifetimes are shown on Fig. 8.

Fig. 8

ET microparameters of $\mathrm{Tm}^{3+}$ in $\mathrm{ZB}(\mathrm{L}) \mathrm{AN}$ glasses for the ${ }^{3} \mathrm{H}_{4}$ level reported in literature [19] are: $\mathrm{C}_{\mathrm{SS}}=2.810^{-51} \mathrm{~m}^{6} / \mathrm{s}, \mathrm{C}_{\mathrm{SA}}=310^{-51} \mathrm{~m}^{6} / \mathrm{s}$. Values reported by Balda [20] where the host material was $\mathrm{TeO}_{2}-\mathrm{WO}_{3}-\mathrm{PbO}$ glass and Burshtein model applied are $\sim 10^{-51}$ $\mathrm{m}^{6} / \mathrm{s}$. Values of $5.1510^{-51} \mathrm{~m}^{6} / \mathrm{s}$ obtained by Yokota-Tanimoto fit on the ${ }^{3} \mathrm{H}_{4}$ decay curve of $\mathrm{Tm}^{3+}$ in $\mathrm{TeO}_{2}-\mathrm{CdCl}_{2}$ glass is reported by [23]. $\mathrm{C}_{\mathrm{SA}}$ parameter from this study obtained by Yakota-Tanimoto fitting for the sample $\mathrm{T} 1$ is of the same order of magnitude as in the literature whilst by parameter extension by fitting gives higher values. Both parameters, $\mathrm{C}_{\mathrm{SA}}$ and $\mathrm{C}_{\mathrm{SS}}$ showed good range of order by inserting them to ET constant and comparing obtained lifetime values with the experimental results.

\subsection{Concentration quenching of the ${ }^{3} \mathbf{F}_{4}$ emission}

Concerning the ${ }^{3} \mathrm{~F}_{4}$ emission, the relative luminescence intensity increases while its lifetime decreases with concentration. Figure 9 shows the logarithmic plot of the experimental decays of the ${ }^{3} \mathrm{~F}_{4}$ level for all samples. As can be seen the decays can be described by an exponential function to a good approximation for all concentrations and the lifetime decreases as concentration increases. Lifetime values and the corresponding quantum efficiency for the ${ }^{3} \mathrm{~F}_{4}$ emission are reported in Table 5. 
Fig.9

In this case, where the ${ }^{3} \mathrm{~F}_{4}$ level is the first excited state, the quenching of luminescence when active ion concentration increases can not be due to cross-relaxation between various excited states and it has been mainly considered as due to diffusion towards unidentified impurities (such as $\mathrm{OH}$ or other impurities present in the starting materials). The problem can be separated into two cases: diffusion limited regime and fast diffusion. The first case is considered when the order of magnitude for transfer probability between sensitizers and sensitizer to activator are the same. As we have seen, in the case of the diffusion limited situation the quenching rate is proportional to the square of concentration. As it is shown in Fig. 5 a logarithmic plot of the quenching rate of level ${ }^{3} \mathrm{~F}_{4}$ as a function of $\mathrm{Tm}^{3+}$ concentration gives a slope close to 2 , which indicates that we are dealing with a diffusion limited regime. In such a case, and assuming a dipole-dipole interaction, the self quenching behavior can be described by the formula proposed by Auzel [24]:

$$
\tau=\frac{\tau_{0}}{1+\frac{9}{2 \cdot \pi}\left(\frac{N}{N_{0}}\right)^{2}}
$$

where $\tau$ is measured lifetime at given concentration $\mathrm{N}, \tau_{0}$ is lifetime for low concentrations i.e. radiative lifetime, $\mathrm{N}_{0}$ as the critical sensitizer concentrations is linked with critical distance between sensitizer and trap as $R_{0}=\left(\frac{3}{4 \cdot \pi \cdot N_{0}}\right)^{1 / 3}$. By fitting of experimentally obtained lifetime 
values on the above formula (Fig. 10) the following characteristic parameters can be obtained: $\tau_{0}=(3.29 \pm 0.07) \mathrm{ms}, \mathrm{N}_{0}=(4.2 \pm 0.1) 10^{20} \mathrm{~cm}^{-3}, \mathrm{R}^{2}=0.997, \mathrm{R}_{0}\left({ }^{3} \mathrm{~F}_{4}\right)=8.3 \AA \rightarrow \mathrm{C}_{\mathrm{SA}}=9.810^{-53}$ $\mathrm{m}^{6} / \mathrm{s}$.

\section{Fig.10}

Experimental values are in very good agreement with the fit curve for the whole range of concentrations. ET parameter is lower than in the case of ${ }^{3} \mathrm{H}_{4}$ level by three orders of magnitude and the critical radius, shorter.

\section{Conclusions}

The present study concerns the investigation of various highly doped $\mathrm{Tm}^{3+}$ tellurite glasses in order to provide optimum dopant concentration for short cavity laser. Lifetime values of low doped sample have been measured and the obtained values of 3.09 and $0.347 \mathrm{~ms}$ for ${ }^{3} \mathrm{~F}_{4}$ and ${ }^{3} \mathrm{H}_{4}$ level, respectively. The optimum emission intensity at $1.8 \mu \mathrm{m}$ considering single ion was obtained for the concentration of $6.8410^{20} \mathrm{~cm}^{-3} \mathrm{Tm}^{3+}$ with $24 \%$ quantum efficiency. For such a high dopant concentration CR process strongly quenches emission from ${ }^{3} \mathrm{H}_{4}$ level. An analysis of the fluorescence decays of the ${ }^{3} \mathrm{H}_{4} \rightarrow{ }^{3} \mathrm{~F}_{4}$ emission as a function of concentration reveals that the electronic mechanism responsible for the ion-ion interaction is a dipole-dipole quenching process in the framework of a diffusion-limited regime. The self-quenching of the $1.8 \mu \mathrm{m}$ emission can be attributed to limited diffusion within the active centers. This means that the probability for the diffusive steps between active centers is of the same order of magnitude than the one for quenching between impurities and centers. A critical sensitizer concentration for self quenching of $4.210^{20} \mathrm{~cm}^{-}$ 
${ }^{3}$ was obtained. This dopant concentration could be extended to the $6.8410^{20} \mathrm{Tm}^{3+}$ with a satisfactory QE in order to obtain short cavity fiber laser devices.

\section{Acknowledgments}

The authors wish to thank the Regione Piemonte Converging Technologies "Hipernano" research project. R. Balda and J. Fernández acknowledge financial support from the Spanish Ministerio de Ciencia e Innovacion under project MAT2009-14282-C02-02 and from the Basque Country Government (IT-331-07).

\section{References}

[1] Masayuki Yamane, Yoshiyuki Asahara, Glasses for Photonics, Cambridge University Press, ISBN-13: 9780521580533, p. 131., 2004.

[2] W.E.K. Gibbs, D.J. Booth, V.K. Bogdanov, Population dynamics of the ${ }^{3} \mathrm{~F}_{4}$ and ${ }^{3} \mathrm{H}_{4}$ levels in highly-doped $\mathrm{Tm}^{3+}: \mathrm{ZB}(\mathrm{L}) \mathrm{AN}$ glasses, Journal of Non-Crystalline Solids, 353, (2007).

[3] A. Godard, Infrared $(2-12 \mu \mathrm{m})$ solid-state laser sources: a review C. R. Physique, 8, (2007).

[4] J. F. Digonnet, Rear -Earth doped fiber laser and amplifiers, sec. edition, Marcel Dekker, p. 627, (2001). 
[5] Encyclopedia of Laser Physics and Technology, RP - Photonics, http://www.rpphotonics.com

[6] H. Gebavi, D. Milanese, G. Liao, Q. Chen, M. Ferraris, M. Ivanda, O. Gamulin, S. Taccheo, Spectroscopic investigation and optical characterization of novel highly thulium doped tellurite glasses, J. Non. Cryst. Solids, vol. 355, no 9, p.548 - 555, (2009).

[7] R. Rolli, M. Montagna, S. Chaussedent, A. Monteil, V.K. Tikhomirov, M. Ferrari, Erbium-doped tellurite glasses with high quantum efficiency and broadband stimulated emission cross section at $1.5 \mu \mathrm{m}$, Optical Materials 21, 743-748, (2003).

[8] B. M. Walsh, Norman P. Barnes, Donald J. Reichle, Shibin Jiang, Optical properties of $\mathrm{Tm}^{3+}$ ions in alkali germanate glass, J. of Non-Crystalline Solids 352, 5344-5352, (2006).

[9] Elizabeth R. Taylor, Li Na Ng, and Neil P. Sessions, Herbert Buerger, Spectroscopy of $\mathrm{Tm}^{3+}$-doped tellurite glasses for $1470 \mathrm{~nm}$ fiber amplifier, J. Appl. Phys., vol. 92, no. 1, (2002).

[10] J. Alloys and Compounds 436 (2007) 216.

[11] Yong Gyu Choi, Doo Hee Cho, Kyong Hon Kim Influence of 4f absorption transitions of $\mathrm{Dy}^{3+}$ on the emission spectra of $\mathrm{Tm}^{3+}$-doped tellurite glasses, J. Non-Crystalline Solids, $276,1-7,(2000)$ 
[12] Craig A. Evans, Zoran Ikonic, Billy Richards, Paul Harrison, Animesh Jha, Numerical Rate Equation Modeling of $\mathrm{a} \sim 2.1 \mu \mathrm{m} \mathrm{Tm} \mathrm{Tm}^{3+} / \mathrm{Ho}^{3+}$ Co-Doped Tellurite Fiber Laser, J. Lightwave Tech., vol. 27, no. 19, (2009).

[13] D. F. de Sousa, R. Lebullenger, A. C. Hernandes, L. A. O. Nunes, Evidence of higherorder mechanisms than dipole-dipole interaction in $\mathrm{Tm}^{3+}-\mathrm{Tm}^{3+}$ energy transfer in fluoroindogallate glasses, Phy. Rev. B, vol. 65, (2002).

[14] M. Ajroud, M. Haouari1, H. Ben Ouada, 1, H. Mâaref, A. Brenier, and B. Champagnon, Study of the spectroscopic properties and infrared-to-visible up-conversion fluorescence of $\mathrm{Er}^{3+}$-doped germanate glasses, Phys. stat. sol., 202, no. 2, 316-329, (2005).

[15] J.R. Lakowicz, Principles of fluorescence spectroscopy, Kluwer Academic/Plenum Publishers, New York, (1999).

[16] B.M. Walsh, Review of Tm and Ho Materials; Spectroscopy and Lasers, Laser Physics, vol.19. no. 4., p. 855-866, (2009).

[17] Marvin J. Weber, Luminescence decay by energy migration and transfer; Observation of diffusion - limited relaxation, Phy. Review B, vol. 4, 9, (1971).

[18] F. Auzel, F. Bonfigli, S. Gagliari, G. Baldacchini, The interplay of self-trapping and selfquenching for resonant, transitions in solids; role of a cavity, J. of Lumin. 94-95, 293-297, (2001). 
[19] W.E.K. Gibbs, D.J. Booth, V.K. Bogdanov, Population dynamics of the ${ }^{3} \mathrm{~F}_{4}$ and ${ }^{3} \mathrm{H}_{4}$ levels in highly-doped $\mathrm{Tm}^{3+}: \mathrm{ZB}(\mathrm{L}) \mathrm{AN}$ glasses, J. Non-Crystalline Solids, 353, 1-5, (2007).

[20] R. Balda, L.M. Lacha, J. Fernandez, M. A. Arriandiaga, J.M. Fernandez-Navarro, D. Munoz-Martin, Spectroscopic properties of the $1.4 \mu \mathrm{m}$ emission of $\mathrm{Tm}^{3+}$ ions in $\mathrm{TeO}_{2}-\mathrm{WO}_{3^{-}}$ PbO glasses, Opt. Express, vol.16, no.16, (2008).

[21] A.S.S. de Camargo, S.L. de Oliveira, D.F. de Sousa, L.A. O. Nunes, D.W.Hewak, Spectroscopic properties and energy transfer parameters of $\mathrm{Tm}^{3+}$ ions in gallium lanthanum sulfide glass, J. Phys. Condens. Matter 14 , 9495-9595, (2002).

[22] D. F. de Sousa, L. A. O. Nunes, Microscopic and macroscopic parameters of energy transfer between $\mathrm{Tm}^{3+}$ ions in fluoroindogallate glasses, Phy. Review B 66, 024207, (2002).

[23] A. Sennaroglu, A. Kurt, G. Ozen, Effect of cross relaxation on the 1470 and $1800 \mathrm{~nm}$ emissions in $\mathrm{Tm}^{3+}: \mathrm{TeO}_{2}-\mathrm{CdCl}_{2}$ glass, J. Phys.: Condens. Matter 16, 2471-2478, (2004).

[24] F. Auzel, F. Bonfigli, S. Gagliari, G. Baldacchini, The interplay of self-trapping and selfquenching for resonant, transitions in solids; role of a cavity, J. of Lumin. 94-95, 293-297, (2001). 


\section{Tables}

Table 1. Concentration and refractive indexes for Tm-doped 75T-20Z-5N glasses

\begin{tabular}{ccccccc}
\hline Sample name & $\begin{array}{c}\mathbf{T m}^{\mathbf{3 +}} \\
\left.\mathbf{x 1 0}^{\mathbf{2 0}} \mathbf{c m}^{-\mathbf{3}}\right)\end{array}$ & $\mathbf{n}(\mathbf{6 3 3 n m})$ & $\mathbf{n}(\mathbf{8 2 5 n m})$ & $\mathbf{n}(\mathbf{1 0 6 1} \mathbf{n m})$ & $\mathbf{n}(\mathbf{1 3 1 2 n m})$ & $\mathbf{n}(\mathbf{1 5 3 3 n m})$ \\
\hline T0 & 0 & 2.0514 & 2.0243 & 2.0091 & 2.0012 & 1.9962 \\
$\mathbf{T 0 . 3 6}$ & 0.82 & 2.0488 & 2.0224 & 2.0077 & 1.9998 & 1.9950 \\
$\mathbf{T 1}$ & 2.28 & 2.0454 & 2.0189 & 2.0046 & 1.9965 & 1.9918 \\
$\mathbf{T 2 . 1}$ & 4.87 & 2.0412 & 2.0152 & 2.0007 & 1.9928 & 1.9880 \\
T3 & 6.84 & 2.0396 & 2.0136 & 1.9994 & 1.9917 & 1.9867 \\
T4 & 9.06 & 2.0356 & 2.0097 & 1.9954 & 1.9983 & 1.9833 \\
T5 & 11.3 & 2.0306 & 2.0053 & 1.9913 & 1.9839 & 1.9792 \\
T6 & 13.5 & 2.0268 & 2.0021 & 1.9879 & 1.9805 & 1.9761 \\
T7 & 15.7 & 2.0239 & 1.9993 & 1.9853 & 1.9780 & 1.9733 \\
T10 & 22.1 & 2.0116 & 1.9878 & 1.9746 & 1.9672 & 1.9629 \\
\hline
\end{tabular}

* T0 signs host composition

Table 2. J-O parameters comparison with literature.

\begin{tabular}{c|ccc}
\hline Reference & $\mathbf{\Omega}_{\mathbf{2}}$ & $\boldsymbol{\Omega}_{\mathbf{4}}$ & $\mathbf{\Omega}_{\mathbf{6}}$ \\
\hline$[8]^{*}$ & 3.38 & 2.17 & 1.17 \\
{$[10]^{*}$} & 4.64 & 1.61 & 1.26 \\
{$[11]^{* *}$} & 5.106 & 1.174 & 1.082 \\
This study $*$ & 4.4 & 1.97 & 1.22
\end{tabular}

* host composition: $75 \mathrm{TeO}_{2}-20 \mathrm{ZnO}-5 \mathrm{Na}_{2} \mathrm{O}$

** host composition: $80 \mathrm{TeO}_{2}-10 \mathrm{ZnO}-10 \mathrm{Na}_{2} \mathrm{O}$

$* * * \Omega\left[10^{-20} \mathrm{~cm}^{2}\right]$

Table 3. Transition rates, radiative lifetimes, and branching ratios

\begin{tabular}{|c|c|c|c|c|}
\hline Transition & $\bar{\lambda}(\mathbf{n m})$ & $\mathbf{A}_{\mathbf{J}^{\prime} \mathbf{J}}\left(\mathbf{s}^{-1}\right)$ & $\boldsymbol{\tau}_{\mathbf{0}}(\mathbf{m s})$ & $\boldsymbol{\beta}$ \\
\hline${ }^{1} \mathrm{G}_{4} \rightarrow{ }^{3} \mathrm{H}_{6}$ & 470 & 2803.82 & 0.19 & 0.5445 \\
\hline
\end{tabular}




\begin{tabular}{|c|c|c|c|c|}
\hline${ }^{1} \mathrm{G}_{4} \rightarrow{ }^{3} \mathrm{~F}_{4}$ & 646 & 354.99 & & 0.0689 \\
\hline${ }^{1} \mathrm{G}_{4} \rightarrow{ }^{3} \mathrm{H}_{5}$ & 763 & 1446.24 & & 0.2808 \\
\hline${ }^{1} \mathrm{G}_{4} \rightarrow{ }^{3} \mathrm{H}_{4}$ & 1177 & 442.71 & & 0.0859 \\
\hline${ }^{1} \mathrm{G}_{4} \rightarrow{ }^{3} \mathrm{~F}_{3}$ & 1494 & 102.07 & & 0.0198 \\
\hline${ }^{3} \mathrm{~F}_{3} \rightarrow{ }^{3} \mathrm{H}_{6}$ & 686 & 4396.45 & \multirow{4}{*}{0.2} & 0.8381 \\
\hline${ }^{3} \mathrm{~F}_{3} \rightarrow{ }^{3} \mathrm{~F}_{4}$ & 1138 & 118.43 & & 0.0226 \\
\hline${ }^{3} \mathrm{~F}_{3} \rightarrow{ }^{3} \mathrm{H}_{5}$ & 1558 & 724.36 & & 0.1381 \\
\hline${ }^{3} \mathrm{~F}_{3} \rightarrow{ }^{3} \mathrm{H}_{4}$ & 5552 & 6.36 & & 0.0012 \\
\hline${ }^{3} \mathrm{H}_{4} \rightarrow{ }^{3} \mathrm{H}_{6}$ & 784 & 2685.6 & \multirow{3}{*}{0.36} & 0.9035 \\
\hline${ }^{3} \mathrm{H}_{4} \rightarrow{ }^{3} \mathrm{~F}_{4}$ & 1432 & 226.71 & & 0.0762 \\
\hline${ }^{3} \mathrm{H}_{4} \rightarrow{ }^{3} \mathrm{H}_{5}$ & 2166 & 60.25 & & 0.02 \\
\hline${ }^{3} \mathrm{H}_{5} \rightarrow{ }^{3} \mathrm{H}_{6}$ & 1225 & $459.6_{\mathrm{ED}}+113.3_{\mathrm{MD}}$ & \multirow{2}{*}{1.71} & 0.9793 \\
\hline${ }^{3} \mathrm{H}_{5} \rightarrow{ }^{3} \mathrm{~F}_{4}$ & 4226 & 12.12 & & 0.0207 \\
\hline${ }^{3} \mathrm{~F}_{4} \rightarrow{ }^{3} \mathrm{H}_{6}$ & 1725 & 488.13 & 2.1 & 1 \\
\hline
\end{tabular}

Table 4. Lifetime values comparison

\begin{tabular}{|c|c|c|c|c|c|}
\hline Transition & $\begin{array}{c}\boldsymbol{\tau}_{\mathbf{0}}(\mathbf{m s}) \\
\text { This study }\end{array}$ & $\begin{array}{c}\boldsymbol{\tau}_{\mathbf{0}}(\mathbf{m s}) \\
\text { exp. values }\end{array}$ & $\begin{array}{c}\boldsymbol{\tau}_{\mathbf{0}}(\mathbf{m s}) \\
{[\mathbf{8}]}\end{array}$ & $\begin{array}{c}\boldsymbol{\tau}_{\mathbf{0}}(\mathbf{m s}) \\
{[\mathbf{9}]}\end{array}$ & $\begin{array}{c}\boldsymbol{\tau}_{\mathbf{0}}(\mathbf{m s}) \\
{[\mathbf{1 0}]}\end{array}$ \\
\hline${ }^{3} \mathrm{~F}_{4} \rightarrow{ }^{3} \mathrm{H}_{6}$ & 2.1 & 3.09 & 3 & 2.13 & 2.1 \\
${ }^{3} \mathrm{H}_{5} \rightarrow{ }^{3} \mathrm{H}_{6}$ & 1.71 & NA & NA & 1.88 & 1.63 \\
${ }^{3} \mathrm{H}_{4} \rightarrow{ }^{3} \mathrm{H}_{6}$ & 0.36 & 0.347 & 0.35 & 0.37 & 0.34 \\
${ }^{3} \mathrm{~F}_{3} \rightarrow{ }^{3} \mathrm{H}_{6}$ & 0.2 & NA & NA & NA & 0.24 \\
${ }^{1} \mathrm{G}_{4} \rightarrow{ }^{3} \mathrm{H}_{6}$ & 0.19 & NA & NA & NA & 0.19 \\
\hline
\end{tabular}

Table 5. Lifetime values of ${ }^{3} \mathrm{H}_{4}$ and ${ }^{3} \mathrm{~F}_{4}$ level with corresponding quantum efficiency

\begin{tabular}{|c|c|c|c|c|c|}
\hline Sample name & $\begin{array}{c}\mathrm{Tm}^{3+} \\
\times 10^{20}\left(\mathrm{~cm}^{-3}\right) \\
\end{array}$ & $\begin{array}{l}{ }^{3} \mathrm{H}_{4} \\
(\mu \mathrm{s}) \\
\end{array}$ & $\begin{array}{c}\eta\left({ }^{3} \mathbf{H}_{4}\right) \\
\%\end{array}$ & $\begin{array}{l}{ }^{3} \mathbf{F}_{4} \\
(\mathbf{m s}) \\
\end{array}$ & $\begin{array}{c}\eta\left({ }^{3} \mathbf{F}_{4}\right) \\
\%\end{array}$ \\
\hline T0.36 & 0.82 & 347 & 100 & 3.09 & 100 \\
\hline T1 & 2.28 & 147 & 42.4 & 2.42 & 78.3 \\
\hline T2.1 & 4.87 & 32 & 9.2 & 1.06 & 34.3 \\
\hline T3 & 6.84 & 18 & 5.2 & 0.74 & 23.9 \\
\hline T4 & 9.06 & 7 & 2 & 0.42 & 13.6 \\
\hline T5 & 11.3 & 7 & 2 & 0.32 & 10.4 \\
\hline T6 & 13.5 & 5 & 1.4 & 0.14 & 4.5 \\
\hline T7 & 15.7 & 4 & 1.2 & 0.14 & 4.5 \\
\hline T10 & 22.1 & 4 & 1.2 & 0.04 & 1.3 \\
\hline
\end{tabular}

Table 6. Obtained values of the Yakota - Tanimoto fitting parameters 


\begin{tabular}{c|c|c|c|c|c|c}
\hline${ }^{3} \mathbf{H}_{\mathbf{4}}$ level & $\begin{array}{c}\mathbf{A} \\
\left(\mathbf{s}^{-\mathbf{1} / 2}\right)\end{array}$ & $\begin{array}{c}\mathbf{B} \\
\left(\mathbf{s}^{-\mathbf{2} / 3}\right)\end{array}$ & $\begin{array}{c}\mathbf{R}^{\mathbf{2}} \\
(\mathbf{\%})\end{array}$ & $\begin{array}{c}\mathbf{C}_{\mathbf{S A}} \\
\mathbf{1 0}^{-\mathbf{5 0}}\left(\mathbf{m}^{\mathbf{6}} / \mathbf{s}\right)\end{array}$ & $\begin{array}{c}\mathbf{D} \\
\mathbf{1 0}^{-\mathbf{1 4}}\left(\mathbf{m}^{\mathbf{2}} / \mathbf{s}\right)\end{array}$ & $\begin{array}{c}\mathbf{R}_{\mathbf{0}} \\
(\mathbf{A})\end{array}$ \\
\hline $\mathbf{T 1}$ & $119 \pm 1$ & $92 \pm 3$ & 99.65 & 0.49 & 0.16 & 10.9 \\
$\mathbf{T 2 . 1}$ & $400 \pm 4$ & $491 \pm 14$ & 99.27 & 1.23 & 1.13 & 12.7 \\
$\mathbf{T 3}$ & $616 \pm 7$ & $744 \pm 18$ & 98.48 & 1.47 & 1.82 & 13.1 \\
\hline
\end{tabular}

$* \mathrm{R}^{2}$ is the square of the correlation coefficient

\section{Figure captions}

Fig.1. Absorption cross section of $\mathrm{Tm}^{3+}$ doped TZN glass

Fig. 2. Emission spectra of thulium ${ }^{3} \mathrm{H}_{4}$ and ${ }^{3} \mathrm{~F}_{4}$ levels. All the spectra are normalized on the area under ${ }^{3} \mathrm{H}_{4}$ peak.

Fig. 3a) Emission ratio presents the ratio between area under ${ }^{3} \mathrm{~F}_{4} \rightarrow{ }^{3} \mathrm{H}_{6}$ and ${ }^{3} \mathrm{H}_{4} \rightarrow{ }^{3} \mathrm{~F}_{4}$ emission bands. The line is a guide to the eye.

Fig. 3b) Ratio between the areas under the ${ }^{3} \mathrm{~F}_{4} \rightarrow{ }^{3} \mathrm{H}_{6}$ and ${ }^{3} \mathrm{H}_{4} \rightarrow{ }^{3} \mathrm{~F}_{4}$ emission bands normalized to the number of ions.

Fig. 4. Lifetime decay curves of ${ }^{3} \mathrm{H}_{4}$ level. Exponential decay is only in the case of sample T0.36

Fig. 5. Logarithmic dependence of quenching rate and dopant concentration. Curve slopes for both ${ }^{3} \mathrm{H}_{4} \rightarrow{ }^{3} \mathrm{H}_{6},{ }^{3} \mathrm{~F}_{4} \rightarrow{ }^{3} \mathrm{H}_{6}$ transitions are around 2 . 
Fig. 6. Yokota-Tanimoto fit for ${ }^{3} \mathrm{H}_{4}$ level of the sample T1.

Fig. 7a) Yokota - Tanimoto fit parameter $\mathrm{A}$ as a function of concentration: $\mathrm{A}=(1.089 \pm 0.003)$ $10^{-24} \mathrm{~N}$

Fig. 7b) Yokota - Tanimoto fit parameter $\mathrm{B}$ as a function of $\mathrm{N}^{4 / 3}$ concentration: $\mathrm{B}=$ $(1.4 \pm 0.1) 10^{-33} \mathrm{~N}^{4 / 3}$

Fig. 8. Calculated and measured lifetime values of the ${ }^{3} \mathrm{H}_{4}$ level. Deviation from experimental values is smaller for higher dopant concentrations.

Fig. 9. Decay curves of ${ }^{3} \mathrm{~F}_{4}$ emissions. Sample T1 shows non-linear behavior.

Fig. 10. Experimental data of ${ }^{3} \mathrm{~F}_{4}$ level fitted on theoretical curve. Values of $8.3 \AA$ for critical distance and corresponding $\mathrm{N}_{0}=(4.2 \pm 0.2) 10^{20} \mathrm{~cm}^{-3}$ and ET microparameter $9.810^{-53} \mathrm{~m}^{6} / \mathrm{s}$ are obtained. 
Figures

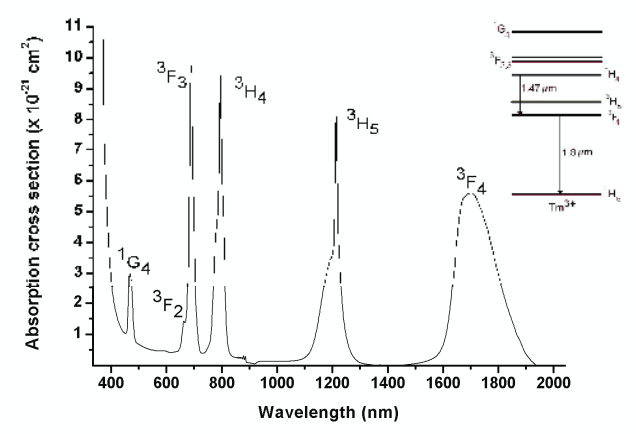

Fig. 1.

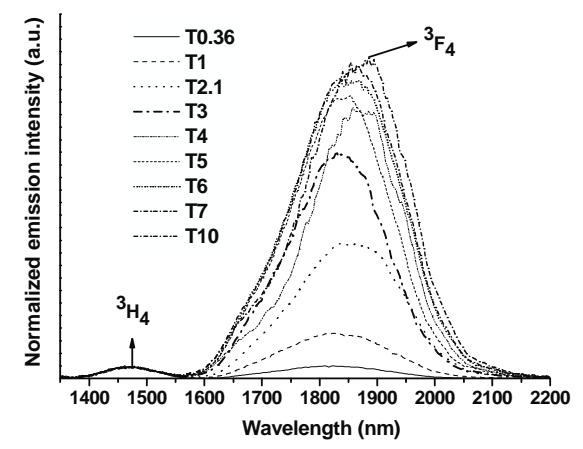

Fig. 2. 


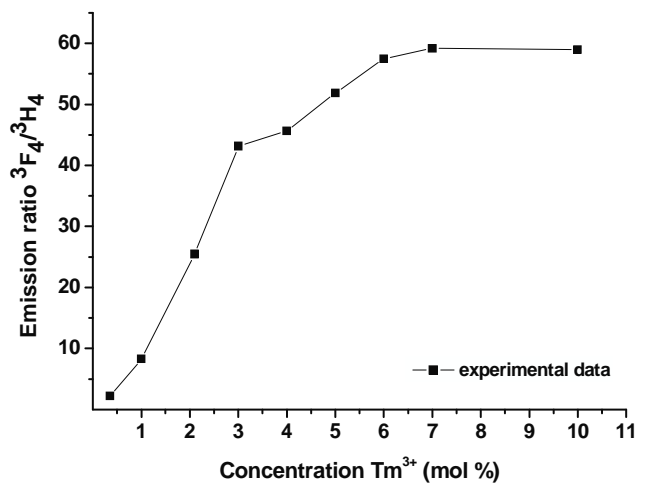

Fig. 3a)

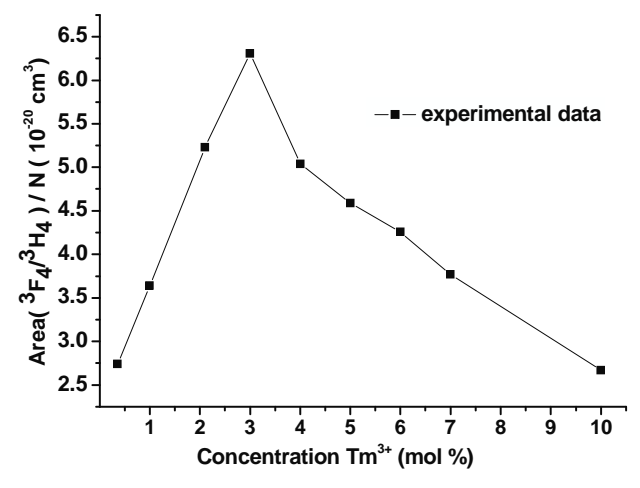

Fig. 3b)

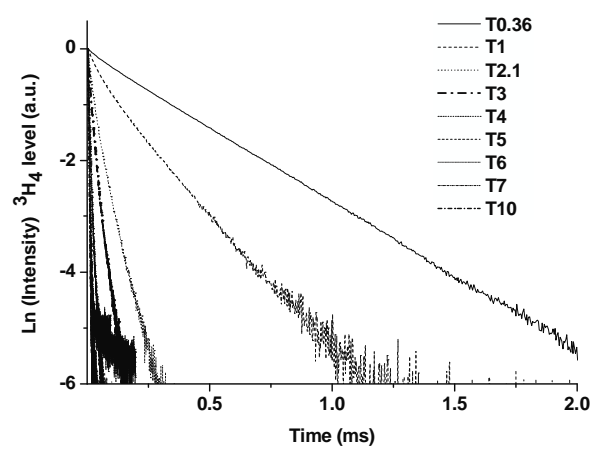

Fig. 4. 


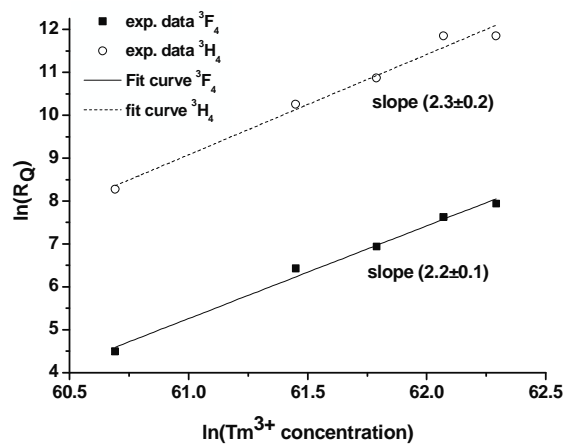

Fig. 5.

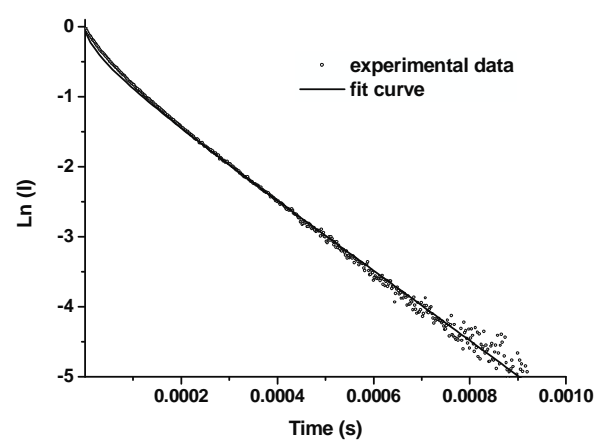

Fig. 6.

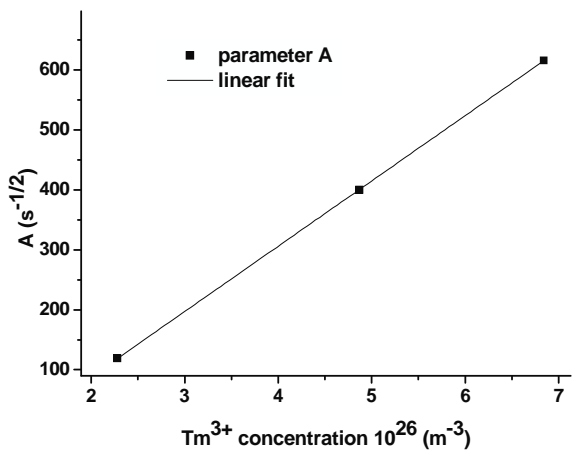

Fig. 7a)

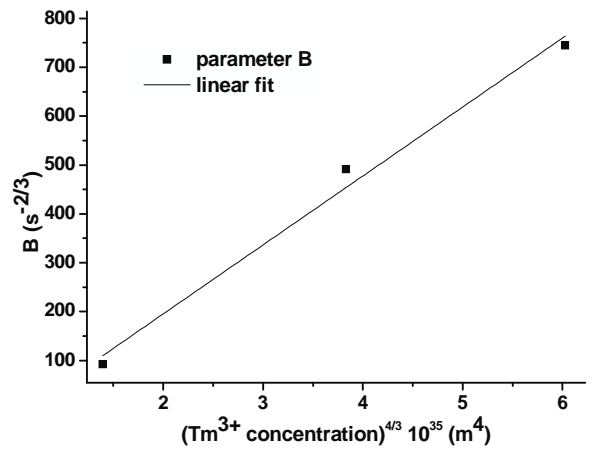

Fig. 7b) 


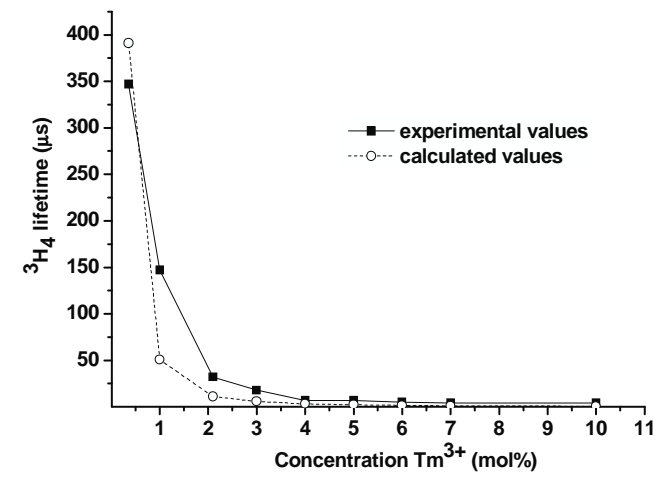

Fig. 8 .

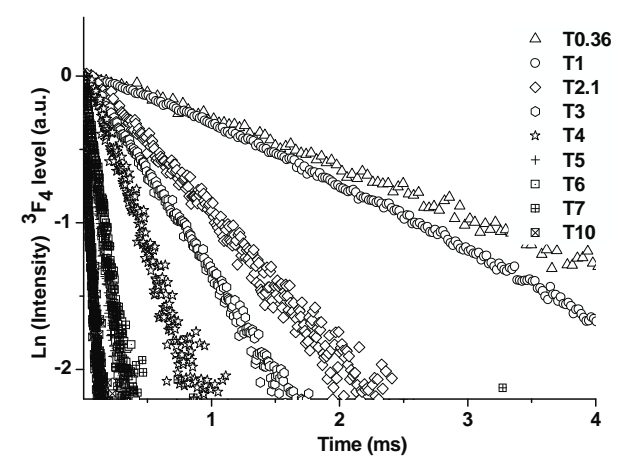

Fig. 9.

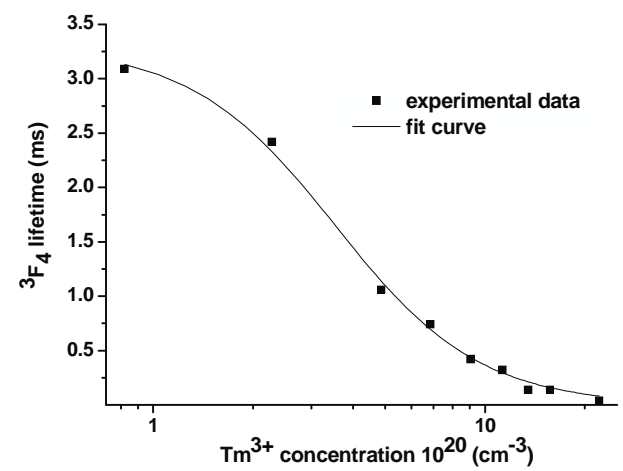

Fig. 10. 
